\title{
Nörobilimin Örgütsel Davranışa Yansıması: Örgütsel Nörobilim
}

\author{
Reflection of Neuroscience on Organizational Behaviour: Orgazational Neuroscience
}

\author{
Oytun Boran SEZGIN', Zeki UÇAR ${ }^{1}$
}

\begin{abstract}
ÖZET
Örgüt ve yönetim biliminin temellerinin atıldığı 1900'lü yılların başından günümüze kadar birey, grup, örgüt ve popülasyon düzeyinde doğrudan ve dolaylıolarakmetaforikyaklaşımlardan esinlenen sayısız analiz birimi ve analiz düzeyinde çeşitli çalışmalar yapılmıştır. Bu farklı çalışmaların, insan beynindeki etkileşimleri dikkate almaması örgüt ve yönetim alanı içerisinde bir eksiklik olarak karşımıza çıkmaktadır. Son günlerde önemi iyice açığa çıkan ve yazında yerini sağlamlaştıran örgütsel nörobilimin, nörogörüntüleme tekniklerinden faydalanarak bu alana çok daha zengin bir bakış açısı getirdiği bir gerçektir. Özellikle psikoteknik değerlendirmelerin yanında kullanılacak olan nörogörüntüleme tekniklerinin yönetimci ve bilimci bakış açılarını genişletecek ve yeni kapılar aralayacaktır.
\end{abstract}

Anahtar kelimeler: Örgütsel Davranış, Nörobilim, Örgütsel Nörobilim.

\section{GíRiş}

İnsan biyolojisinin öneminin farkına varan yönetim bilimciler, var olan görgül bilgilere dayalı olarak insan biyolojisinin örgütsel davranış üzerindeki etkisini evrimsel psikoloji, davranışsal genetik ve fizyolojik değişim olarak sınıflandırmaktadırlar (Becker vd., 2011:935). Ancak son dönemde nörobilimsel alanda yaşanan kayda değer gelişmeler ve bunun örgütsel alana yansıması, bu yeni araştırma düzleminin örgütsel davranış bağlamında eskimeyecek bir bakış açısını ortaya çıkarmaktadır. Bu noktada, birçok araştırmacı insan beyninin derinlemesine araştırılmasının yönetim bilim ve uygulamalarına yarar sağlayacağını önermektedir (Bagozzi vd., 2013:1572; Becker ve Cropanzano, 2010:1056). Örgütsel nörobilim (organizational neuroscience), yeni bir çözüm önerisi getirilememiş var olan sorunların yanı sıra güncel sorunlara da ışık tutan farklı bir bakış açısı ya da yorumsal bir çerçeve olarak çok iyi bir düşünceyi yansıtmaktadır (Becker ve Cropanzano, 2010: 1059). Ancak ilgili yazın incelendiğinde, alanın kavramsallaştırılması üzerinde tam olarak fikir birliğinin sağlanmadığı görülmektedir. Dolayısıyla, bu çalışmanın temel ilgi odakları:

\begin{abstract}
From the years 1990s -that management and organization field laid its foundations- to today, various of studies have been done in different units and levels of analysis which were inspired directly or indirectly by metaphorical approaches conducted at the level of individual, group, organizations and the population. These studies take into account of the interactions in human brain and fill a hole in the literature of management and organization. Organizational neuroscience, a science which has gained importance and secured its position recently, brought a much richer perspective to the management and organization field as using neuroimaging techniques. Particularly, using neuroimaging techniques beside psycho-technique evaluations will broaden the perspectives of managerial and scientific perspectives and will open new doors.
\end{abstract}

Keywords: Organizational behaviour; neuroscience; organizational neuroscience.

- Türk yönetim yazınına yeni olan "örgütsel nörobilim" kavramını tanıtmak,

- Çalışmalarda benzer ama farklı isimlerle adlandırılan kavramının Türk yazınında çeşitlenmeden kavramsallaştırmasına katkıda bulunmak,

- Uygulamacılara nörobilimden örgütsel alanda nasıl faydalanılabilecekleri konusunda yeni bir bakış açısı oluşturmaktır.

\section{2. ÖRGÜTSEL NÖROBILLIMIN TARIHÇESI}

İnsanların nasıl duyduğu, gördüğü, ne şekilde hatırladığı, öğrendiği, unuttuğu ya da bazı şeylerin iyi hissettirip bazı şeylerin kötü hissettirmesinin nedenleri konusunda meraklı olunması insanoğlunun doğasında bulunmaktadır. Bu merakın doğurduğu gizemin irdelenmesi ise nörobilim araştırmalarının temellerini atmıştır. Beynin içerisindeki nöral aktivitelerin incelenmesi olarak tanımlanan nörobilim, aslında beynin ilk varlığından beri hayatın içerisinde bulunmaktadır. Antik Mısır, Antik Yunan ve Roma Imparatorluğu dönemlerine ait insan kafatası kalıntılarını inceleyen arkeologlar, günümüzden yaklaşık 7000 yıl önce beyin ameliyatları yapıldığının kanıtlarını ortaya 
koyarak, bu alanda yapılan araştırma ve çalışmaların o dönemlerden günümüze kadar uzandığına vurgu yapmaktadırlar. Çalışmalar bu kadar eskilere dayanmasına karşın nörobilim olarak adlandırılan bilimsel çerçeve 1970'lerde çizilmiştir. (Bear vd., 2007:4-6). Bu bilimsel devrime temel olan çalışmalar Sherrington'ın (1947) 1906'da başladığı araştırmalarından oluşturduğu "Sinir Sisteminin Bütünleyici Faaliyetleri" (The Integrative Action of the Nervous System) ve Nöron Öğretisi'ni (Neuron Doctrine) ortaya koyan Cajal'dır(http://www.columbia.edu/cu/psychology/ courses/1010/mangels/neuro/history/history.html). Günümüzde ise nörobilim araştırmaları çok daha büyük boyutlardadır; Avrupa Birliği, "Human Brain Project" ile 10 yıllık kapsamda beyinin işleyişini anlayarak insanı insan yapan değerleri ve hastalıkları çözmeyi amaçlayarak birçok araştırmacıyı bünyesinde toplamıştır (https://www.humanbrainproject.eu/). Amerika Birleşik Devletleri'nde ise 2013 yılı içerisinde BRAIN (Brain Research through Advancing Innovative Neurotechnologies) adı verilen girişim sayesinde ileri inovatif nöroteknolojiler ile beyin araştırmalarına hız verilmiştir (http://www.nih.gov/science/brain/).

Nörobilim alanı hızlı gelişimini sürdürürken farklı bilim dalları ile ortaklaşa gelişen çalışmalar sonucu, çok disiplinli yeni çalışma alanlarının ortaya çıktığı görülmektedir. Bu bilim dallarından birisi de bilişsel bilimdir (Cognitive Science). Biliş, duyumlama, algılama, dikkat, öğrenme, hafıza, dil, düşünme ve akıl yürütmeyi de içeren bilginin edinimi ve kullanımındaki zihinsel süreçlerdir. (McGraw-Hill Science \& Technology Encyclopedia' dan aktaran Akpunar, 2011: 356). Dolayısıyla bilişsel bilimin ilk ve en önemli amacı algı, öğrenme ve karar verme gibi mekanizmaları anlamaya çalışmaktır. Bilişsel bilim bu gayeyle çeşitli modeller önermektedir. Geliştirilen bu modeller, insanların yaptıkları hataları, bazı zamanlar neden tepki gösterdiklerini, farklı koşullar altındaki davranışların nasıl değiştiğini, farklı uyaranların ne şekilde harekete geçtiğini ve farklı seviyelerdeki öğrenmeyi tahminlemeyi amaçlamaktadır (Palmeri, 2013:67). Kişilerin davranışlarını, tepkilerini ve duygusal durumlarını psikometrik bir ölçümleme ile ortaya koyan bu modeller, bilişsel aktivitelerin temelini teşkil eden beyin içi süreçleri göz ardı etmektedir. Beyindeki nöral etkileşimlerin modeller içerisinde olmayışı, aslında yapbozun eksik ve en önemli parçasıdır. Ancak, adına "nörobilim" denilen ve temel ilgi alanını ileri teknolojiler kullanarak beyin iç yapısı ve süreçlerini gözlemlemek olan yeni bir bilim alanı, insan beynini incelenebilir hale getirerek, bilişsel bilim için gizemin kapılarını ardına kadar aralamaktadır. Bu sayede ortak bir paydada buluşan araştırmacılar "bilişsel nörobilim" (Cognitive Neuroscience) adında yeni bir bilim alanının inşasına girişmektedirler.
Bilişsel bilimin, nörobilim ile kesişim düzlemi olan "bilişsel nörobilim" zihinsel süreçlerin beyinde nasıl gerçekleştiğini nöronal altyapıları ile ortaya koymayı amaçlamaktadır. Diğer bir ifade ile bilişsel nörobilim çalışmaları dikkat, belleğe kaydetme, hatırlama ve soyutlama gibi süreçlerin beyin yapısı içerisinde oluşturmuş olduğu zihinsel etkileşimi belirlemeyi hedeflemektedir (Ergen ve Ülman, 2012:149-150). Kafatasının üzerine yerleştirilen elektrotlar yardımıyla, beyindeki elektriksel ve manyetik dalgaların ölçülebilmesi ve beyinin uyarılmasının bölgesel incelenebilmesi (Scherg, 1990:41-42) zihinsel süreçler ile biyolojik tepkilerin ilişkilendirilmesine olanak açmıştır.

Bu ilişkiler, nöropsikolojik, elektropsikolojik ve fMRI (functional magnetic resonance imaging) gibi teknikler kullanarak insan beyninin içine yoğunlaşmaktadır. Bu sayede bilişsel modellemeler insan beyninin farklı deneysel koşullar altındaki zihnini haritalandırmaya çalışarak, karmaşık davranışları belirli sembol ve süreçlere ayrıştırmaktadır (Palmeri, 2013:67).

Bir yanda biliş modellemeleri hafıza, dikkat, hatırlama gibi süreçleri nörobilimden faydalanarak açıklamaya çalışırken diğer tarafta biliş bilimi ile insan davranışlarının açıklanabileceği bakış açısı da gelişim göstermiştir. İnsan davranışlarının nasıl şekillendiğini "biliş" ile açıklamaya çalışan Miller ve Dollard (1941) Sosyal Öğrenme Teorisi'ni geliştirmişlerdir. Teori, yeni davranışın öğrenilmesinde dürtü, ipucu, tepki ve ödül gibi dört temel faktörün olduğunu ortaya koyarken aynı zamanda kişinin yeni bir davranışı öğrenmesi konusunda motivasyonu bulunduğunda, o davranışın aynı kişi tarafından gözlemlenerek de öğrenildiğini savunmaktadır. Bandura (1977:39-41) ise Sosyal Öğrenme Teorisi'nin de değindiği insan davranışının ve davranışı kontrol eden faktörlerin sadece bireysel ve çevresel faktörlere dayalı olarak açıklanması konusuna ilişkin bazı eksikliklere dikkat çekmekte ve katkı sağlamaktadır. Sosyal Biliş Teorisi'ni geliştiren Bandura (1988:276) insan davranışının açıklanmasında kişisel ve çevresel faktörlerin yanında bilişin de çift yönlü olarak etkileşim içinde bulunduğunu ortaya koymaktadır. Bandura'nın (1988) insan zihnindeki biliş süreçleri ile davranışın açıklanabileceğini ortaya koyduğu Sosyal Biliş Teorisi'nin devamında iddiasına destek olabilecek çalışmaların da ardı ardına geldiği dikkate değer bir durumdur. Bevan (1991:475) bireyin psikolojik durumunun entelektüel girişimlerini etkilediğini ve bunun da davranışsal bilim dallarının doğasında bulunan insanların sosyalleşmesine etkide bulunduğunu bildirmektedir. Leshner (1991:977) ise çalışmasında, Zihin Sağlığı Ulusal Enstitüsü'nde (NIMH) araştırmaların biyolojik, davranışsal ve bu iki 
alanın etkileşimi bakış açılarıyla gerçekleştiğine vurgu yapmaktadırlar. Bütün bu bilgiler ışığında, insanların davranışlarını anlayabilmemiz onların sosyal dünyayı nasıl algıladıkları ve bu algının nasıl belirlendiği noktalarından hareketle sağlanabilir. Bu bağlamda değerlendirilmesi gereken bir kavram olarak karşımıza "sosyal bilişs" (Social Cognition) çıkmaktadır. Sosyal biliş, kişilerin, kendileri ve diğer kişiler hakkındaki değerlendirmelerinin oluştuğu süreç içerisinde nelere dikkat ettikleri, bu değerlendirmeleri ne şekilde algıladıkları ile hatırladıkları ve farklı sosyal durum ya da koşulların bu tür biliş süreçlerini nasıl etkilediğini incelemektedir (Pennington, 2000).

Tarihsel süreç içerisinde, bilişsel bilimin sosyal bilimler ve nörobilim ile yakın zaman süreçlerinde ortaklaşa çalışmalar içerisine girmesi ve bu alanlara biliş biliminin ilgisinin artması sonucunda, insan davranışının nöral düzlemde araştıııması kaçınılmaz bir hale getirmiştir. Bu iki alanın ortak bir zeminde bulaşabileceği anlayışının ortaya çıkmasıyla birlikte, sosyal psikologların ve nörobilimcilerin ortaklaşa çaış̧masının gerekliliğine vurgu yapılmaktadır. Cacioppo ve Berntson (1992:1019) indirgemecilik anlayışının ötesine geçerek resme daha geniş açıdan bakılması gerektiğini, bunun da ancak sosyal nörobilim (Social Neuroscience) ve/veya "sosyal bilişsel nörobilim" (Social Cognitive Neuroscience) aracılığıyla olabileceğine dikkat çekmektedirler.

Ochsner ve Lieberman (2001:719) sosyal bilişsel nörobilim yaklaşımını, kişisel olarak ilgilenilen durumlardaki motive olmuş bireylerin, davranış ve tecrübeleriyle (sosyal düzey) bu durumlara ilişkin farkındalık yaratan bilgi işleme mekanizmalarına (bilişsel düzey) ve bu süreci simgeleştiren beyin sistemlerine (doğal düzey) kadar uzanan çok düzeyli bir alan olarak tanımlamaktadırlar. Araştırmacılar alanın sosyal psikologlar ve bilişsel nörobilimciler için yeni bir kapı açtığına vurgu yapmaktadırlar. Bu yeni kapının getirdiği ortak bakış sayesinde sosyal psikologların çeşitli olaylarla ilgili olarak geliştirdikleri teorileri nörobilim verileri ile test edebileceklerini, bilişsel nörobilimcilerin ise sosyal olayları incelerken insanların kendilerini ya da diğerlerini nasıl algıladığını, nasıl hissettiğini, nasıl karar verdiğini açıklayan zengin sosyo-psikolojik faktörlerden faydalanabileceklerini iddia etmektedirler.

2000'den itibaren sosyal bilişsel nörobilimi destekleyen birçok çalışma karşımıza çıkmaktadır. Blakemore vd. (2004:216) sosyal bilişin birey ya da grup seviyesinde aynı türdeki canlıların bilişsel süreçlerini ifade ettiğini belirtmekte ve sosyal bilişsel nörobilimin algı, dil, hafıza ve dikkat gibi bilişsel süreçlerin sosyal yetkinliğe ve sosyal etkileşime etkisini irdelemektedirler. Adolph (2003:175) bireysel ve toplu davranış- ların yönlendiricisi olan sosyal yapıların şekillendirmiş olduğu sosyal uyarıcıların algılanması ve yargılanması sürecinin bireylerin sosyal bilişsel yeteneğine bağlı olduğunu iddia etmektedir. Lieberman (2007:260) sosyal bilişsel nörobilimin diğerlerini anlama, kendini tanıma, otokontrol ve diğerleri ile etkileşim süreçlerini birleştiren geniş bir alan olduğunu belirtirken; Ochsner (2004:256) ise çalışmasında sosyal bilişsel nörobilimin sosyal etkileşimi anlamaya yol gösteren bir rehber olduğunu ifade etmektedir.

Nörobilimin sosyal etkileşimleri anlamaya faydası olacağına inanan görüşlerin çoğalması, nörogörüntüleme tekniklerinin sosyal bilimlerde kullanılmasının da önünü açmıştır. Özellikle bu tekniklerden faydalanılarak "nöroiktisat" (neuroeconomics) ve "nöropazarlama" (neuromarketing) kavramları ortaya atılmıştır.

Glimcher ve Rustichini (2004:452) nörobilim ve ekonominin ortaklaşa çalışarak uygulayacakları nöroiktisadi programlar sayesinde çok önemli faydalar sağlanabileceğine dikkat çekmektedirler. Sonraki çalışmasında bu iki disiplini ortak bir zeminde buluşturmaya gayret gösteren Rustichini (2005:201) nöroiktisat olarak kavramsallaştırdığı bu ortak düzlemi, nörobilimin içeriğinin, yönetiminin ve teknik araçlarının ekonomik analizlerde kullanılması olarak tanımlamaktadır. Nöroiktisatın iktisadi kararlar üzerinde beynin etkisini araştıran Cameerer vd. (2004:10) çalışmalarında nörobilimsel ve iktisadi yöntemleri birleştirmektedir. Davranışsal iktisat alanında insanların reklamların etkisiyle alma kararlarını etkileyen noktaların açığa çıkmasına yardımcı olacak nöroiktisatın (Braeutigram, 2005:359), özellikle iktisat modellerinin bireylerin nasıl farklılaştığını açıklayabilen tatmin edici bir teorisi olmaması konusunda ise alana yeni bir kapı aralayabileceği (Camerer, vd., 2005:54) belirtilmektedir. Böylece içsel mi rasyonel mi tartışmaları içersindeki iktisat bilimi ne gözlemlenebilen ne de ölçülebilen davranış teorilerin oluşturduğu dilemmayı çok daha objektif bir yolla çözüme ulaştırabilme fırsatını nöroiktisat ile elde edilebilecektir (Kenning ve Plassmann, 2005:343). Örneğin davranışsal iktisat çalışmaları ve sosyal bilişsel nörobilim disiplinlerinin çalışma alanlarını birleştirmeleri ile David (2011) iktisadi etkileşimlerde oluşan işbirliği, rekabet, adillik ve güvenle ilişkilendirilen nörol tepkileri incelenme olanağı bulunabileceğini belirtmektedirler.

Nöroiktisadi çalışmaların ekseninde Lee vd. (2007:200) norobilimi pazarlama disiplini içerisine taşımışlardır. Araştırmacılar tarafından "nöropazarlama" olarak kavramsallaştırılan bu yeni çok disiplinli alan, nörogörüntüleme teknikleri uygulayarak potansiyel müşterilere ürünleri satabilmek olarak tanımlanmaktadır. Nöropazarlamaya ilişkin farklı bir çalışmada, 
nöropazarlama teknikleri sayesinde elde edilebilecek faydaları irdeleyen Fugate (2007: 391-392), farklı uyarıcıların insanlar üzerinde farklı etkileri faaliyete sokacağını, pazarlama tekniklerinde bunun dikkate alınması gerekliliğini bildirmektedir.

Sosyal bilimlerdeki nörobilime doğru artan bu ilginin, doğal olarak zamanla yönetim bilimi yazınına da sıçradığı görülmektedir. Butler ve Senior (2007:8) çalışmalarında örgütsel bilişsel nörobilim (organizational cognitive neuroscience) olarak adlandırdıkları kavramı aynı nöroiktisat ve nöropazarlamada olduğu gibi örgüt içerisindeki bireylerin davranışlarının anlaşılması ve analiz edlimesi için nörobilim tekniklerinin kullanılması olarak tanımlamaktadırlar.

Becker ve Cropanzano (2010) çalışmalarında nörobilimin örgütsel davranış alanına uygulanmasına dönük üç öneri sunmaktadırlar. Bu öneriler (Becker ve Cropanzano, 2010:1056-1058):

1. Ağırdan alma (procastination) ile mücadele: Hedef seçimi ve sürdürme

\section{Ayna (yansıyan) nöronlar ve grup alt iklimi}

3. Tutum ve davranış: Tutum değişime karşı nasıl direnç oluşturulur?

Becker ve Cropanzano (2010:1056) ağırdan almayı belirlenmiş amaç ve yönlendirmelere ilişkin acilen gerçekleştirilmesi gereken eylemleri ertelemeyi içeren kendi kendini engellemeye dönük bir davranış olarak tanımlamaktadır. Örgütsel alanda sıkça karşılaşılan bu duruma ilişkin Reddish ve çalışma arkadaşları (2008:416-417) karar alma sistemlerinin bağımlılıklara karşı nasıl savunmasız kalacağını irdeledikleri çalışmaları ile nörobilim araştırmalarının hedef yönelimli davranışların neden ağırdan almaya karşı savunmasız kaldığını ortaya koyabilme adına değerli bir bakış açısı sağlayacağını bulgulamaktadırlar.

Sonuç olarak, zorlu hedefleri gerçekleştirmek, alışkanlık ve homeostatik tepkilerin üstesinden gelmeyi gerektirmektedir. Nörobilim, işleri ertelemeye neden olan karar verme sistemlerindeki bu zayıflıkların üstesinden gelmek için mümkün bir yol önermektedir. Genel olarak konuşursak, mevcut durumu değiştirmek bir çözümdür ve böylece bilinçli planlama sistemine geçilebilir. Bir kere planlama sistemi içerisine sirayet eden kendi kendini yavaşlatma eğilimi sökülüp atıldı mı, bireyler yüksek olasılıkla arzu edilen hedefleri takip etmek ve başarmak için arzulu olacaklardır (Becker ve Cropanzano, 2010:1057).

Ayna nöronlar ise, uyumcul amaçlar için insanoğlunun beynini sosyal etkilere açık hale getirmek için donatmışlardır. İlk olarak makak (macaque) maymunlarında gözlemlenmesiyle keşfedilen ayna nö- ronlar daha sonra yapılan çalışmalarda insanoğlunun da sahip olduğu bir özellik olarak karşımıza çıkmaktadir (Rizzolatti ve Craighero, 2004: 169; Keysers, 2010: 971). İnsanoğlunun sahip olduğu bu nöron sistemi sadece hedef yönelimli eylemlerin görsel olarak gözlemlenmesine değil aynı zamanda dinamik hareket, yüz ifadeleri ve sese tepki vermektedir. Gözlemcinin sanki gözlemlenen kendisiymiş gibi beyinsel olarak tepki vermesi kişinin kendini başkalarının yerine koyarak öğrenmesini kolaylaştırmaktadır. Keysers'e göre (2010: 973) diğerlerinin sergilemiş oldukları eylemler, insanların algısına katkıda bulunmaktadır.

Bu durumla bağlantılı olarak sosyal nörobilim, grup içi ilişkiler ve örgütsel araştırmalar için yeni bir seçenek oluşturmaktadır. Bu araştırmalarla nörobilim bakış açısının bütünleştirilmesi daha da gelişmiş bir teori için hayati olacaktır. Spesifik olarak insanoğlunun ayna nöron sistemi (ANS) sözlü olmayan iletişim, gizli koordinasyon, hedeflerin benzeşmesi, niyetler ve hatta diğerlerinin mental durumlarını içeren sosyal işlevlerin birçok çeşidini kuvvetlendirecektir. ANS bağımsız iş takımları içerisinde örgütsel iklimin nasıl ortaya çıktığını anlamak için bir mekanizma sağlayabilir. Bu bakış açısı çalışma grupları içerisinde örgütsel iklimden ayrı olarak farklı alt iklimlerin nasıl geliştiğini de açıklayabilir. Ayrıca örgüt kültürünü değiştirmek için girişilen yukarıdan aşağı girişimlerin neden başarısız olduğunu göz önüne koyabilir (Becker ve Cropanzano, 2010:1057).

Becker ve Cropanzano'nun (2010:1058) yönetim alanında nörobilimin kullanılabileceği son alanı tutum ve davranış olarak belirtmektedir. Örgütsel değişim çabalarının sıklıkla başarısızığa uğramasının sebebi olan direnç, kişilerin sahip oldukları tutumlarıyla ilgilidir. Nörobilim bu konuya ilişkin üç farklı tutum tipinin önemli olduğunu bildirmektedir: ima edici, açık ve ifade edilen. Özellikle direnci kırabilmek gizli ve açık tutumların ortaya konmasının önemine değinen Becker ve Cropanzano (2010), bunu sağlayabilmenin yolunun ise nörobilimden geçtiğini iddia etmektedir.

Örgütsel davranış alanında sosyal bilişsel nörobilim, nöro-örgütsel davranış gibi farklı şekillerde adlandırılan örgütsel nörobilim gittikçe önemini hissettirmektedir. Kavramı sosyal bilişsel nörobilim olarak adlandıran Lieberman (2007:260) bilişsel nörobilim yöntemlerini sosyal bilimlerden çeşitli teori ve sorularla birleştirmektedir. Poldrack (2006:59) ise örgütsel nörobilim kavramını nöro-örgütsel davranış olarak adlandırmaktadır. Beugré (2010:289-290) nöro-örgütsel davranış (Neuro-OB) olarak tanımlamış olduğu çalışma alanını, alışılagelmiş örgütsel davranış çalışmalarından farklı olarak örgütlerdeki insan davranışIarını araştıran çalışmalarda, nörobilimsel yöntemleri 
kullanmak olarak belirtmektedir. Ancak nöro-örgütsel davranış çok disiplinli bir çalışma alanı olarak bilişsel psikoloji, nöroiktisat, nörobilim, örgütsel davranış ve sosyal bilişsel nörobilim alanlarının kullanmış olduğu yöntem ve bilgileri kullanmaktadır (Beugré, 2010:292). Son dönemlerde özellikle doğrudan beyin aktivitelerini görüntüleme yöntemlerinde artış gözlemlenmektedir. Bu durum sosyal bilişsel nörobilim alanlarında yapılan çalışmaların örgütsel davranış çalışmalarında da beyin aktivitelerini gözlemlemek için gerekli olan koşulların çok kısa bir sürede gelişebileceğine işaret etmektedir.

\section{3. ÖRGÜTSEL NÖROBILIME YARDIMCI TEKNOLOJIK ARAÇLAR}

Örgütsel davranışa yeni bir soluk getiren örgütsel nörobilim çalışmalarının gerçekleştirilebilmesi için nörobilim alanının faydalandığın teknolojik araçlar ve modelleme teknikleri ön plana çıkmaktadır. Çeşitli ileri teknolojileri içeren nöro-görüntüleme yöntemleri doğrudan ve dolaylı olarak beynin yapı ve fonksiyonlarını görüntüleyerek ölçmeye yardımcı olmaktadır. Bu yöntemler iki kategoriye ayrılmaktadır. Bunlar yapısal görüntüleme ve işlevsel görüntülemedir. Yapısal görüntüleme beyin yapısı ve tümör gibi beyin boşluğunda yer alan maddi rahatsızlıkların teşhisiyle ilgilenmektedir. Beynin merkezi tarafından bilgilerin işlenmesini doğrudan görüntüleme imkanı sağlayan işlevsel görüntüleme ise nöronlara zarar veren Alzaymır gibi psikolojik kökenli hastalıkların tınlanmasında kullanılmaktadır (Waldman vd., 2011:1095).

Örgütsel davranış alanına ilişkin araştırma sorularının nöral düzeyde ölçümlenmesinde karşılaşılan asıl zorluk uygun nöro-görüntüleme tekniğinin seçilmesi ve uygulanmasını içermektedir. Günümüzde bir dizi teknik insan davranışlarının beyin ile olan ilişkisini araştırmamıza yardım etmek için dikkate alınabilir. Örgütsel nörobilim alanında faydalanabilecek teknikler ve araçlar şu şekilde sıralanabilir: (1) Bilgisayarlı Tomografi Taraması (CT scan/computerized axial tomography scan), (2) Pozitron Emisyon Tomografisi (PET/positron emission tomography), (3) Fonksiyonel Manyetik Rezonans Görüntüleme (FMRI/functional magnetic resonance imaging), (4) Elektroensefalografi (EEG) , (5) kortizon seviyesi ölçümü ve (6) cilt iletkenliği ölçülmesidir (Waldman, 2011:1095; Becker ve Menges, 2013:221-225).

\section{4. ÖRGÜTSEL DAVRANIŞ YAZININDA ÖRGÜTSEL NÖROBILIM KONUSUNDAKI ÇALIŞMALAR}

Peterson (2005:391-392) yapmış olduğu çalışmada Stanford Üniversitesi SPAN laboratuarlarında Brian
Knutson tarafından yürütülen çalışmayı temel almaktadır. Stanford Üniversitesi'nde yapılan deneysel nitelikteki bu çalışmada, finansal etkinlikler esnasında temel nöral aktivasyonlar ile duygu, davranış ve biliş ilişkilendirmek için denekler fMRI ile gözlemlemektedir. Bu çalışmadaki asıl amaç davranışların tahminlenebilir modellerini geliştirmektir. Peterson bu noktadan hareketle yüksek düzeyde belirsizlik ve risk altında faaliyet gösteren finansal pazarlarda yatırımcıların kişisel davranışlarını tahminlemek ve anlamayı amaçlamıştır. Bu sayede rasyonel olmayan yatırımcı davranışları ve anormal finansal piyasa fiyat kalıplarını, ödül sisteminin fMRI araştırmalarından elde edilen bulguların korelasyonu ile analizlerini gerçekleştirmektedir.

Balthazard vd. (2012:253-254) tarafından sivil ve askeri birimlerden 200 lider üzerinde gerçekleştirilen çalışmada dönüşümcü ve dönüşümcü olmayan liderlerin farklııklarını nörolojik görüntülemeye dayalı olarak ortaya çıkarmak ve sınıflandırmak amaçlamaktadırlar. Bu araştırmada liderin takipçilerinin algılarını ölçmeye yönelik mevcut psikometrik ölçüm yöntemleri ve nörolojik bir yöntem olan elektroensefalografi (EEG) yöntemiyle beyin üzerine konumlandırılan 19 algılayıcıdan veriler kaydetmişlerdir. Araştırmacıların EEG güç spektral analizini kullanarak beynin prefrontal ve frontal temporal (şakak), merkezi ve yan ve oksibital lobları (alanları) üzerinde yoğunlaşan sinyalleri dönüşümcü liderlik özelliği gösteren ve göstermeyen liderlerle ilişkilendirmektedirler.

Bagozzi vd. (2013:1784-1785) farklı bir bakış açısıyla makyevelizmi ve örgüt içerisindeki işlevini örgütsel bilişsel nörobilim ile irdelemektedirler. Araştırmacılar bu bağlamda makyavelizmi kuvvetlendirdiğini düşündükleri ve ayrıca örgüt teorisi ve psikoloji biliminde sıklıkla kullanılan iki boyut üzerine odaklanmaktadırlar. Yaptıkları deneylerde kişilerin performanslarındaki makyevelist davranışlarını mentalizm ve duygusal zekâ boyutlarına dayandırarak nörogörüntüleme teknikleri ile ölçmüşler ve yüksek makyevelistlerin yakından kontrol varlığında düşük satış performansı gösterirken, kontrol azaldıkça satış performansının artığını belirtmektedirler. Aynı zamanda bu sonuçların düşük makyevelistlerde ise tam tersi olduğunu göstermektedirler. Ayrıca örgütlerdeki işgörenlerin örgüt ve birey yönelimli örgütsel vatandaşılılarının yakından kontrol ile ilişkisinde makyevelist davranışların düzenleyici rolü olduğunu bulgulamaktadırlar.

Sadler-Smith ve çalışma arkadaşları (2008:45) girişimcilik davranışına yönelen kararların verilmesinde sezgilerin etkilerini incelemektedirler. Sezgilerin anlaşılmasında ise kişilerin dışavurumlarının üzerine yapılan araştırmalara (Somatic Marker Hypothesis) değinen araştırmacılar özellikle çift yönlü işleyen sü- 
reçlerin girişimcilik yargılarının verilmesinde ve anlaşılmasında olumlu etkisi olduğunu bildirmektedirler. Araştırmacılar ayrıca, vücut alanındaki incelemelerin yönetim, örgüt ve girişimcilik alanına katkıda bulunduğunu iddia etmektedirler.

Campell vd. (2009:62-66) çok yetkin olan liderlerin bazı konularda niye hatalı kararlar verdiklerini incelemiş oldukları çalışmalarında, kişilerin önceki geçmiş deneyimleri ile karar aldıkları tanıdık desenler (recognition pattern) ve duygusal etiketleme (emotional tagging) durumuna göre karar almalarının hatalara sebep olduğunu iddia etmektedirler. Çalışmaları, tanıdık desenlere ve duygusal etiketlemeye sebep olan "kırmızı bayrak durumları" olarak adlandırdıkları üç başlık altında toplanmaktadır. Bu başlıklar uygun olmayan kişisel çıkarın varlığı, çarpıtılmış bağlılığın varlığı ve yanlış yönlendiren anıların varlığıdır. Araştırmacılar, hatalara sebep olan bu kırmızı bayrak durumlarını anlayabilmenin ve ortaya çıkarabilmenin yolunu beyni analiz eden nörobilim ile mümkün olacağını bildirmekedirler.

Becker ve Menges (2013) örgütsel nörobilimi insan kaynakları yönetimi uygulamaları açısından incelemektedirler. Araştırmacılara göre İKY açısından insanların iş yeri davranışları altında yatan örtülü sebepleri ortaya koymak bireysel ve örgütsel performans açısından önem taşımaktadır (Becker ve Menges, 2013:220). Becker ve Menges (2013:221-224) görgül bir çalışma gerçekleştirmemelerine karşın kişilerin davranışlarının altında yatan örtülü gerçeklerin sebep olduğu biyolojik sonuçları ve bu sonuçların nörobilimde kullanılan hangi öngörülmeme teknikleri ile ölçülebileceğini iredelemektedirler.

Boyatzis vd. (2011:261) gerçekleştirdikleri çalışmada 8 profesyonel işgörene daha önceki uyumlu ve uyumsuz liderlerle ilgili tecrübelerinden bahsetmekte ve bu mülakat sırasında nörogörünteleme tekniği olan fMRI'dan faydalanarak beyinlerindeki nöron faaliyetlerini gözlemlemektedirler. Çalışma sonucunda uyumsuz liderlerin beyinde negatif duygular yaratan bölgeleri harekete geçirirken duygusal tehlikeyi frenleme konusunda bireye yardımcı olacak bilişsel süreçlerin de oluştuğu bulgulamaktadırlar. (Boyatzis vd., 2011:268-269).

Aziz-Zadeh vd. (2009:908) psikologların genellik- le zor sorunların çözümüne yönelik üç genel sorun çözme sınıflaması üzerinde durduklarını belirtmektedirler. Bunlar araştırma, kavrama ve hafızadan çağırmadır. Araştırmacılar kavrayıcı çözümlerin (bir anda sorunun ne olduğunu belirlenmesi) diğer iki çözüm türünden bilişsel süreçleri bakımından güçlü bir şekilde farklı olduğu düşündükleri çalışmalarında, kavrayıcı çözümlerin nöral ilişkilerinin ne olduğu sorusuna yanıt aramaktadırlar. Dietrich (2004:1015) kavramanın yalnızca bilginin yeni kombinasyonlarını yaratıcı çalışmaya dönüştürmekte ilk adım olduğunu belirtmektedir. Araştırmacı bu sorunların çözümünde prefrontal corteks'in cephanelik gibi çalıştığını bu sebeple nörogörüntüleme için uygun bir araştırma olduğunu belirtmektedirler. Kavramın daha anlaşılır olabilmesi için Arşimet'in hamamda suyun kaldırma kuvvetini keşfettiği o ana vurgu yaparak "aha moments" ifadesini kullanan Aziz-Zadeh vd. (2009:908) fMRI görüntüleme tekniğiyle gerçekleştirmiş oldukları çalışmada beynin sağ arka bölgesi (right temporal pole) ve sağ ile sol arka spiral köşe (left and right angular gyrus) bölümlerinde kavrama çözümlerine yönelik aktivitelere ilişkin minimal düzeyde bir hareketlilik gözlemlediklerini belirtirken; ayrıca çözüm aramaya ilişkin çabalar esnasında bu bölgelerin neredeyse bütünüyle devre dışı kaldığını iddia etmektedirler (Aziz-Zadeh vd., 2009: 914).

Beugré (2009: 129) yapmış olduğu çalışmada nöroiktisat (neuroeconomics), örgütsel adalet ve sosyal bilişsel nörobilim alanlarında yapılan çalışmalar temelinde nero-örgütsel adalet modeli önermektedir. Araştırmacı örgütsel alanda insanların adalet yargılarının nasıl oluştuğu ve adil olan ve olmayan durumlara karşı nasıl tepki gösterdiklerine ilişkin olarak beynin bu olgular üzerindeki rolünü keşfetmeyi amaçlamaktadır. Beynin çeşitli bölgelerine ilişkilendirilen adil ve adil olmayan durumlar üzerine uygulamalı çalışma sonuçlarından yararlanılmıştır. Araştırmasını genişleten Beugré (2010) örgütlerde adalet, etik ve ahlaki biliş, ödül, değişim ve belirsizlik kavramlarının nöral temellerini nöroiktisadi ve sosyal bilişsel nörobilimsel yaklaşımlarla ele almaktadır. Örgüte yönelik çalışmalarda çok sık karşılaşılan bu olgulara ilişkin algıların insan beyninin hangi kısımlarıyla ilgili olduğu görgül çalışmaların sonuçlarına atıf yapılarak detaylı bir şekilde aktarılmaktadır. 
Şekil 1: Nero-örgütsel Adalet Modeli

\begin{tabular}{|c|c|c|c|}
\hline $\begin{array}{l}\text { *Değişim } \\
\text { *Seçim } \\
\text { *Politikaların } \\
\text { yürürlüğe girmesi } \\
\text { *Adil muamele } \\
\text { *Meslektașlar ile } \\
\text { etkileșim } \\
\text { *Fiziki Çevre } \\
\text { *Ödül sistemi } \\
\text { *Kontrol }\end{array}$ & $\begin{array}{l}\frac{\text { Beynin belirli }}{\text { bölgelerinin }} \\
\text { aktiflesmesi } \\
\text {-Amigdala } \\
\text {-iç insula } \\
\text {-Bazal Ganglia } \\
\text {-Caudate Nucleus } \\
\text { (Kuyruklu Çekirdek) } \\
\text {-Beyin zarı (Kortex) } \\
\text {-Necleus } \\
\text { Accumbens (ödül } \\
\text { merkezi) }\end{array}$ & $\begin{array}{l}\quad \underline{\text { Bilis }} \\
\text { *Bilgi İșleme } \\
{ }^{*} \text { Hafıza } \\
\text { *Ahlaki Ikilem } \\
\text { *Algı } \\
\text { Duygusal Uyarıcı } \\
\text { *Kızgınlık } \\
\text { *Nefret } \\
\text { *Korku } \\
\text { *Kin }\end{array}$ & $\begin{array}{l}\text { *işbirliği } \\
\text { *yaratıcılık } \\
\text { *üretkenlik } \\
\text { * değișime } \\
\text { direnç } \\
\text { *Tatmin }\end{array}$ \\
\hline
\end{tabular}

Kaynak: (Beugré , 2010: 291).

Kısacası Beugre (2010) Şekil 1'de gösterildiği gibi nöral döngüyü aktif hale getiren örgütsel olguya vurgu yapmıştır. Beynin belirli bölgeleri belirli örgütsel olaylarla aktif hale gelmektedir. Bu nöral aktivasyon bilinç ve duygusal uyarılma gibi mental süreçlere neden olmaktadır. Örneğin beyinin bazı kısımları bi-

linçsel süreçlerle aktif olurken diğer kısımlar duygusal uyarıcılarla aktif hale gelmektedir. Bu bakımdan nöro-örgütsel davranış organizasyon içerisindeki insan davranışlarını açıklamak için nöral döngüyü çıkış noktası olarak dikkate almaktadır (Beugré , 2010:291).

Tablo 1: Örgütsel Davranış Alanındaki Örgütsel Nörobilim Çalışmaları ve Kapsamları

\begin{tabular}{|c|c|c|c|c|}
\hline Araştırmacı & Yıl & Kavram & $\begin{array}{l}\text { Görgül } \\
\text { Çalışma }\end{array}$ & Nörogörüntüleme Tekniği \\
\hline Peterson & 2005 & Nörobilim & Var & $\begin{array}{l}\text { Yüksek düzeyde belirsizlik ve risk altındaki } \\
\text { yatırımcıların davranışlarını fMRI ile } \\
\text { ölçümlemiştir. (Beyin ödül sistemi) }\end{array}$ \\
\hline Butler ve Senior & 2007 & Örgütsel Bilişsel Nörobilim & Yok & $\begin{array}{l}\text { Kavramsallaştırma (herhangi bir teknik } \\
\text { kullanılmamıştır) }\end{array}$ \\
\hline $\begin{array}{l}\text { Campell, Whiteheart ve } \\
\text { Finkelstein }\end{array}$ & 2009 & Nörobilim & Yok & $\begin{array}{l}\text { Girişimcilik yetileri (herhangi bir teknik } \\
\text { kullanılmamıştır) }\end{array}$ \\
\hline $\begin{array}{l}\text { Aziz-Zadeh, Kaplan ve } \\
\text { lacoboni }\end{array}$ & 2009 & Nörobilim & Var & $\begin{array}{l}\text { Çözüm aramaya ilişkin çabaları ve kavramayı fMRI } \\
\text { ile çözümlemeye çalışmıştır. }\end{array}$ \\
\hline Beugre & 2009 & $\begin{array}{l}\text { Sosyal Bilişsel Nörobilim, } \\
\text { Nöroiktisat ve Örgütsel } \\
\text { Nörobilim }\end{array}$ & Yok & $\begin{array}{l}\text { Nöro-örgütsel adalet modeli (herhangi bir teknik } \\
\text { kullanılmamıştır) }\end{array}$ \\
\hline Becker ve Cropanzano & 2010 & Örgütsel Nörobilim & Yok & $\begin{array}{l}\text { Kavramsallaştırma (herhangi bir teknik } \\
\text { kullanılmamıştır) }\end{array}$ \\
\hline $\begin{array}{l}\text { Waldman, Balthazard ve } \\
\text { Peterson }\end{array}$ & 2011 & Sosyal Bilişsel Nörobilim & Yok & $\begin{array}{l}\text { Sosyal bilişsel nörobilim ile liderlik arasındaki } \\
\text { ilişkiyi ortaya koyan bir model önerisi (herhangi } \\
\text { bir teknik kullanılmamıştır) }\end{array}$ \\
\hline $\begin{array}{l}\text { Boyatzis, Pasarelli, Koenig, } \\
\text { Lowe, Mathew, Stoller ve } \\
\text { Phillips }\end{array}$ & 2011 & $\begin{array}{l}\text { Nörolojik Etki (Örgütsel } \\
\text { Nörobilim) }\end{array}$ & Var & $\begin{array}{l}\text { İleyicilerin uyumlu ve uyumlu olmayan } \\
\text { liderlere karşı hissettikleri nörolojik etki fMRI ile } \\
\text { ölçülmüştür. }\end{array}$ \\
\hline $\begin{array}{l}\text { Balthazard, Waldman, } \\
\text { Thatcher ve Hannah }\end{array}$ & 2012 & Nörolojik Desen & Var & $\begin{array}{l}\text { Dönüşümcü Liderlik ölçümlenmesinde EEG } \\
\text { tekniğinden faydalanılmıştır. }\end{array}$ \\
\hline $\begin{array}{l}\text { Bagozzi, Verbeke, Dietvorst, } \\
\text { Belschak, Berg ve Rietdijk }\end{array}$ & 2013 & Örgütsel Bilişsel Nörobilim & Var & $\begin{array}{l}\text { Kişilerin makyevelist davranışlarının } \\
\text { ölçümlenmesinde fMRI tekniğinden } \\
\text { faydalanılmıştır. }\end{array}$ \\
\hline Becker ve Menges & 2013 & $\begin{array}{l}\text { Biyolojik Örtülü Ölçüm } \\
\text { (Örgütsel Nörobilim) }\end{array}$ & Yok & $\begin{array}{l}\text { İnsan Kaynakları'na dönük kullanılabilecek } \\
\text { olan nörobilime vurgu (herhangi bir teknik } \\
\text { kullanılmamıştır) }\end{array}$ \\
\hline
\end{tabular}


Liderlik ve nörobilim ile ilgili araştırmaların temellerini oluşturan çalışmalar sağ veya sol beyin loblarını kullanan insanların farklı özelliklere sahip olacağını iddia eden Mintzberg (1976:49) ile alevlenmiştir. Beyinin sağ yarım küresini kullanan kişilerin iyi bir yönetici, sol yarım küresini kullananların ise iyi bir planlamaCı olduklarını savunan Mintzberg (1976:49) dışında da, sol beyin yarım küresi daha baskın olanların daha iyi bir planlamacı olduğu fikri Finkelstein and Hambrick (1996) tarafından da destek görmüştür. Benzer bir fikirle yola çıkan Agor (1983:78) 500 kişi üzerinde yaptığı çalışması sonucunda üst yönetimdeki işgörenlerin orta ve alt düzey yöneticilere göre sağ beyin ölçeğinde daha yüksek puanlar aldıklarını bildirmiştir. Doğal olarak bu görüşün karşısında olanlar eleştirilerini ortaya koymuşlardır. Beyin yarım kürelerinin ayrımlanmasının doğru olmadığını savunan Hines (1987:603-605) özellikle bu çalışmalardaki ölçümleme ve örnekleme gibi yöntem hatalarını ciddi bir biçimde eleştirmiştir. Her ne kadar eleştirel bakanların çalışmalarında haklılık payları olsa da zamanımızda nörogörüntüleme tekniklerindeki gelişme bu sorunların önüne bir set çekmektedir.

Waldman ve arkadaşları (2011b:61) nörobilimin etkili liderliğin tanımlanmasında ve geliştirilmesinde başarılı olduğunu iddia etmektedirler. Kişiliğin psikometrik temelli değerlendirilmesinin liderliğin etkili şekillerinin ortaya konmasında hem pratik hem de teorik olarak yetersizliğine değinmişlerdir. Lord ve Maher (1991) psikometrik değerlendirmelerin problemli konuları olduğunu, bu sebeple geçerliklerinin sorgulanabileceğini iddia etmişlerdir. Psikometrik analizlere oranla nörolojik değerlendirmelerin çok daha uygun bir seçenek olduğunu belirten araştırmacılar, (Becker ve Cropanzano, 2010) nörolojik değişkenlerin liderlerin hareketlerinin ne amaçla yaptığının anlaşılmasına fayda getirdiğini belirtmektedirler. Ek olarak ise lider davranışlarının nörolojik olarak ortaya konmasının inovatif faaliyetlere fayda getireceğini bildirmektedirler.

Bireylerin beyin işlevlerini gerçekleştirirken, psikolojik beyin faaliyetlerini gözlemleyen algılayıcılar ile elde edilen bilgiye yani nöro-geribildirim (Hammond vd. 2011: 55; Hammond, 2011:305-306) gibi araçlar sayesinde liderlik kapasitesini geliştirmenin mümkün olacağı vurgulanmaktadır(Waldman vd., 2011b). İnsanların nasıl karar alıp düşündüklerini ortaya koyan nörobilim sayesinde liderlik becerilerini geliştirmek mümkün hale gelmektedir.

\section{5. ÖRGÜTSEL NÖROBiLIM ALANININ KISITLARI}

Lindebaum (2012) nörobilimin liderlik araştırmalarında kullanılmasında gündeme gelen etik sıkıntılara dikkat çekmiş olduğu çalışmada, öncelikli olarak yapılan çalışmaların bilimselliğine ve gerçekliğine dair eleştiriler getirmektedir. Hiçbir kontrol grubunun olmaması bir yana, insanların gözlemlenmelerinin onların gerçek davranışlarını sergilememesine neden olacağına inanmaktadır. Çalışmasının devamında nörobilim ile elde edilen bilgilerin ışığında en doğru olarak düşünülen lider davranışlarının ayrımcılığa yol açabileceğini iddia etmektedir. Lindebaum (2012) çalışmasında ayrıca "normal" ve "sağlıklı" olarak kabul edilen beyin aktivitelerinin nasıl belirleneceğinin ise bir başka sorunu ortaya çıkardığını belirtmektedir. Cropanzano ve Becker (2013) çalışmalarında Lindebaum'un (2012) getirdiği etik bakış açısını genişletmekte fakat bu teknikler ile fayda sağlayacak kişilerin de göz ardı edilmemesi gerektiğine dikkat çekmektedirler.

Özellikle fMRI uygulaması yüksek maliyeti ve teknik karmaşıklığı açısından bir başka kısıtı yaratmaktadır. Bunun da ötesinde, MRI tekniğini uygulayabilmek kapalı bir alanda, kendine özel bir deneysel tasarımla gerçekleştiği için işyerindeki insanın davranışlarının ne kadar doğru ölçülebildiğini paradigmasını öne çıkarmaktadır (Becker ve Menges, 2013,226).

Ochsner ve Lieberman (2001: 718) nörobilimsel araştırmaların kayda değer ve umut vaat edici olmalarına karşın yapılan herhangi bir araştırmanın yorumlanması esnasında halen önemli teknik ve metodolojik kısıtların bulunduğunu belirtmektedirler.

Ochsner (2004: 256) beyin bölgelerinin bir davranış ya da işlevden daha fazlası için faaliyette bulunduğunu bildirmektedir. Örneğin adil olmayan bir mübadale sonucunda beyin faaliyetinin iğrenme hissi mi yoksa çatışmaya karşı verilen tepkinin duygusu mu olduğunun anlaşılmasının zorluklar içerdiğini belirtmektedir. Bilişsel nörobilimin temel zorluklarından bir diğeri ise nöral faaliyet desenlerinin haritalandırılırken ne şekilde tasarlanacağıdır (Palmeri, 2013:67).

\section{SONUÇ, TARTIŞMA VE ÖNERILER}

Sonuç olarak neden örgütsel davranış alanında nörobilimden faydalanılmalı? Lieberman (2007) insan beynine yönelik nörobilimsel çalışmaların sonucunda belirli amaçlara yönelmiş çoğu beyinsel sürecin bin yıl içerisinde evrim geçirdiğini ve biyolojik olarak 
programlı hale gelen bu süreçlerin sık ve otomatik bir yapıya büründüğünü belirtmektedir. Yakın zaman içerisinde de zihin haritalarının ortaya konması çok daha fazla kapıyı bilim insanları için aralayacaktır. Becker ve Cropanzano (2010: 1055) örgütsel nörobilimin faydalı bir çaba olduğunu belirtmiş oldukları çalışmalarında, örgütsel nörobilimi örgüt bilimi ve nörobilim arasındaki ilişkiyi harekete geçirecek bir köprü olarak bilinçli ve akıllıca ortaya koyulmuş bir yaklaşım olarak tanımlamaktadırlar. Beugré (2010: 298) örgüt araştırmacılarının nörobilimsel yöntemleri örgütsel davranış alanına uygulanmasıyla yönetim kararları ve işgören davranışlarını daha iyi bir şekilde keşfedilebileceğini bildirmektedir. İnsan beyninin anlaşılması ve onun karar verme ve davranışlar üzerindeki etkisi örgüt araştırmacılarına işyerindeki durumlara ilişkin işgörenlerin tepkilerini daha iyi analiz etmelerine yardım edebilir. Ancak bu noktada gerekli teknolojik araçların örgütler tarafından temininin zorluğu, görüntüleme teknolojilerinin maliyetli oluşu ve oldukça spesifik uzmanlık gerektirmesinden dolayı bu araçların yaygın bir şekilde kullanılması yakın zamanda pek mümkün gözükmemektedir. Bu durum bir on yıl sonra bunun böyle kalacağı anlamına gelmemektedir. Nitekim teknolojik değişim ve yeniliklerde yaşanan baş döndürücü ivme, evlerimizde özel alanlar ayırmış olduğumuz kocaman bilgisayarları küçücük cep telefonlarının içine sığdııı hale gelmiştir. Bu yönüyle bakıldığında, örgütsel davranış alanında nörobilimden faydalanma önemle durulması gereken bir gerçeklik olarak karşımıza çıkmaktadır. Bu bakımdan işletmelerin bu günden yarını görerek bu gibi teknolojik süreçlere yabancı kalmamaları gerekmektedir. Böyle bir çalışma en azından Türk Yönetim/Organizasyon yazınının konuya eğilmesi açısından önemlidir.

Günümüzde bilgi, yaratıcılık, yenilikçilik ve girişimcilik gibi kavramlar örgütlerin yaşamlarını sürdürebilmeleri açısından vazgeçilmez hale gelmiştir. Başarılı işletmeler incelendiğinde tüm bu süreçlerin temelinde birey eksenli yatırımların olduğu görülmektedir. İşletmeler açısından bu denli önemli olan bireyin, psikoteknik yöntemlerle ölçülen özelliklerinin nöral düzeyde de teyit edilmesi ya da psikoteknik yöntemlerle ortaya çıkarılamayan bazı olumlu yönlerinin nöral tespitlerle belirlenerek, atıl kalmaktan kurtarılmasının yanı sıra diğer olumsuz özelliklerinin de giderilmesi önemlidir.

Becker ve Cropanzano (2010: 1055) nörobilimsel yöntemlerin geleneksel yöntemlerin yerini almasından ziyade onları tamamladığı belirmektedirler. Diğer bir ifade ile araştırmacıların uzun ve köklü araştırmalar sonucunda üretmiş oldukları araçlardan vazgeçmeden araştırmalarının uygun bulgularını nörobilim- sel yöntemlerle değerlendirmeleri, araştırmalarının daha kapsayıcı olmasını sağlayacaktır. Bu şekilde iş davranışları hakkında önceden bildiklerimizle nörobilimsel bulguları birleştirerek yeni teorik önermelerin formüle edilip test edilebileceğini belirtmektedirler.

Kısacası şu an uygulanan tekniklere çok daha fazIasını sunabilecek, yeni kapılar açabilecek, varoloan bakışı genişletebilecek bir alan olarak örgütsel nörobilim parlak bir seçenek gibi görünmektedir. Özellikle çok karmaşık olan insan davranışını anlamanın zorluğu düşünülecek olursa nörobilimcilerin doğru nörogörüntüleme tekniklerinden faydalanarak ortaya çıkarabilecekleri bilgiler, örgütsel davranış alanına daha bütüncül modeller geliştirilmesine olanak verecektir. Beugre'nin (2010) çalışmasında belirttiği gibi aslında davranışlarımızın temelinde yatan tutumlar beynimizde bulunan sınıflandırmaların bir sonucudur. Karşılaştığımız durumlarla ilgili olarak beynimizde uyarılan bölgeler, olguya ilişkin bilişsel ve duyuşsal tepkilerimizin kaynağını oluşturmaktadır. Örnek olarak örgütsel adalet olgusunun irdelenmesi bu çalışmalardan sadece biridir. Gelecek çalışmalar neredeyse örgütsel davranış içerisinde kalan birçok önemli paradigmayı açıklamada yazılı/sözlü soru sorma, gözlem gibi yöntemlerden çok daha geniş ve çok daha kesin bilgilere ulaşma açısından nörobilim tekniklerinden faydalanarak bilimsel gerçekliğe bizi götürebilir. Bunun yanında nörobilim sayesinde insan davranışına çok daha bütüncül bir bakış ise soyutlanmış olarak insanın tek tek davranışlarının incelenmesinden daha faydalı olacaktır.

Örgütsel nörobilimin, yönetim uygulamalarına dönük önemli katkıları olabilir. Özellikle İnsan Kaynakları uygulamaları açısından yol gösterici olması konusunda nörobilimden yakın zamanda faydalanılacağı çok açıktır. Saygın bir çok insan kaynakları dergisi konunun yükselen bir değer olduğuna dair makaleler yayınlamaktadır (Meisinger, 2013; Waytz ve Mason, 2013; Hills, 2013; Jeffery, 2013; Martindale, 2014). Yöneticiler duyguların anlaşılmasında, ödül sistemi oluşturulmasında, terfilerde, kariyer planlamalarında, yetenek yönetiminde, yaratıcılığın ortaya çıkarılmasında ve çoklu görevin tuzaklarını veya fırsatlarını anlamada nörobilimden faydalanabilirler (Waytz ve Mason, 2013; Hills, 2013).

Meisinger (2013) özellikle işgörenlerin güven, adalet gibi örgütsel kültürün oluşturulmasında önemli katkıları olan duygu olarak adlandırdığımız nöral faaliyetlerin ölçümlenmesinde nörobilim araştırmalarının yönlendirici olacağını, hatta insan kaynakları biriminde yönetici pozisyonundakilerin karşılaşacakları sorunlar sonucunda "Keşke nörobilim doktoram olsaydı" yakınmasında bulunacaklarını belirtmektedir. 
Bunun dışında işgörenlerde motivasyon, doyum gibi performansı doğrudan etkileyen etmenlerin ortaya çıkarılmasında kullanılan ödül sistemlerini ve işgöreni harekete geçirecek hedonik uyarıcıyı bulmakta İnsan Kaynakları biriminin kullanabileceği en etkili yöntem nörobilimdir (Waytz ve Mason, 2013).

Birçok insan kaynakları politikaları ve kültürü, insan beyinin sınırsız bir bilgi ve üretim kaynağı olarak düşünmektedir. Fakat beyin, özellikle çoklu görevler ile ilgilenildiği ve çok karar alma gerekliliği olduğu süresince yorgun düşer ve verimli olamaz (Hill, 2013). Bu noktada işgörenlerin çalışma düzeni ve saatlerinin oluşturulmasında gerekli olan bilgiyi nörobilim sayesinde elde etmek mümkün hale gelmektedir.

Terfiler ya da işe alım gibi insan kaynaklarının temel işlevleri arasında olan görevlerde söz konusu pozisyona atanacak kişinin bu pozisyonun gerektirdiği zihinsel güce (stresi kaldırabilme, duygularını kontrol edebilme, karar verebilme vb.) ve yetkinliğe sahip olup olmadığının anlaşılmasında nörobilim eşsiz bir kaynak olacaktır (Matindale, 2014; Hill, 2013:34). Iki temel düşünme şekillerinden biri yeteneğin doğuştan olduğuna diğeri geliştirildiğine inanmaktadır. Kullanılan yetenek stratejilerinin birçoğu yeteneğin doğuştan varlığını kabul eden bir yönetim olması sebebiyle, ihtiyaç olan pozisyona örgüt dışarısından yeteneği bulma üzerine odaklanmaktadır. Diğer görüş ise bireylerin çok çalışarak elde ettiği deneyim ve öğrenme doğrultusunda yeteneklerini geliştirebileceklerini iddia etmektedir (Hills, 2012:34-35). Yeteneği dışarıdan bulmayı öngören bakış açısından en doğru yeteneği belirlemede nörobilim eşsiz bir kaynak olacaktır. Aynı zamanda yeteneğin geliştirilebileceğine inanan bakış açısına da işgörenlerin eksik yetkinliklerinin belirlenmesi ve eğitilmesi konusunda nörobilim geniş bir kapı aralayacaktır.

İşletmelerin ötesinde nörobilim alanında çok daha geniş çaplı (ulusal), Türkiye'nin bütününü alan projelerin üretilmesi gereklidir. Özellikle girişimcilerin ve girişimciliğin ekonomik büyüme tetiklediği (King ve
Levine, 1993) düşünülürse, ülkenin kendi dinamikleri ve kültüre özgü motifler dâhilinde Türk girişimcisinin davranışsal ve zihinsel özelliklerinin ortaya konmasında nörobilimin faydalı olacağı kanısındayız. Özellikle Amerika Birleşik Devletleri'ndeki BRAiN projesi ya da Avrupa Birliği'ndeki Human Brain Project gibi geniş çaplı nörobilim projeleri ülkenin gelişmesine katkı yapabilir. Örneğin, ülkemizde gerekli eğitimleri alamadığı için girişimci ve yaratıcı özellikleri körelen ya da yeterli desteği bulamadıkları için girişimcilik ve yaratıcılık yönleri atıl kalan bir çok birey bulunmaktadır. Ülkemiz adına çok önemli teknolojik ve ekonomik katma değer sağlayabilecek bu insanların, daha çoçuk yaşlarda tespit edilip eğitilmeleri ve onlara gerekli imkanların sağlanması, gelecekte güçlü bir Türkiye'nin de inşası için temel nitelikte değerlendirilebilir.

Konuyla ilgili bir diğer önemli nokta yabancı yazında kavramın net bir şekilde oluşturulmamış olmasıdır. Kavram üzerinde ortak bir görüş birliğinin olmaması konunun anlaşılabilirliğini ve bütünlüğünü zorlaştırmaktadır. Türk örgüt yazınının bu konuya nispeten daha yeni olması kavram bütünlüğünün baştan oluşturulması için bir fırsat olabilir. Nöro-örgütsel davranış, sosyal bilişsel örgütsel davranış, örgütsel nörobilim şeklindeki farklı kavramlar arasında hepsini daha genelleyici konumdaki "örgütsel nörobilim" bu alanı en iyi tamamlayıcı kavram olarak kullanılabilir.

Bütün bu gelişmeler düşünüldüğünde, örgütsel nörobilim alanına daha fazla ilginin oluşması tarafımızca beklenmektedir. Özellikle teknolojinin gelişmesi ve günümüzde pek kolay erişim olanağı olmayan nörogörüntüleme araçlarının yaygınlaşması, araştırmalarda nörogörüntüleme tekniklerinin kullanımının artmasına neden olacaktır. Örgütsel alandaki davranış çalışmalarının çok daha geniş perspektifte ele alınarak çok daha fazla gerçeğe ulaşılacağını ve bu alandaki bulguların iş yaşamını geliştireceğine inanmaktayız. 


\section{KAYNAKÇA}

Adolphs, R. (2003) “Cognitive neuroscience of human social behaviour" Nature Reviews Neuroscience, 4(3): 165-178.

Agor, W. (1983) "Brain Skills Development in Management Training" Training and Development Journal, 37(4): 78-83.

Akpunar, B. (2011). Biliş Ve Üstbiliş (Metabiliş) Kavramlarının Zihin Felsefesi Açısından Analizi. Electronic Turkish Studies, 6(4): 353-365.

Aziz-Zadeh, L., Kaplan, J. T., ve Iacoboni, M. (2009) “ "Aha!": The Neural Correlates of Verbal Insight Solutions" Human Brain Mapping, 30(3): 908-916.

Bagozzi, R. P., Verbeke, W. J., Dietvorst, R. C., Belschak, F. D., van den Berg, W. E., ve Rietdijk, W. J. (2013) "Theory of Mind and Empathic Explanations of Machiavellianism A Neuroscience Perspective" Journal of Management, 39(7): 1760-1798.

Balthazard, P. A., Waldman, D. A., Thatcher, R. W., ve Hannah, S. T. (2012) "Differentiating Transformational and Non-Transformational Leaders on the Basis of Neurological Imaging" The Leadership Quarterly, 23(2): 244-258.

Bandura, A. (1977) "Social Learning Theory. General Learning Press” New York City 10016.

Bandura, A. (1988) "Organisational Applications of Social Cognitive Theory" Australian Journal of Management, 13(2): 275-302.

Bear, M. F., Connors, B. W., ve Paradiso, M. A. (2007). "Neuroscience" Cilt:2, Lippincott Williams \& Wilkins.

Becker, W. J., ve Cropanzano, R. (2010) “Organizational Neuroscience: The Promise and Prospects of an Emerging Discipline" Journal of Organizational Behavior, 31(7): 1055-1059.

Becker, W. J., Cropanzano, R., ve Sanfey, A. G. (2011) "Organizational Neuroscience: Taking Organizational Theory Inside the Neural Black Box" Journal of Management, 37(4): 933-961.

Becker, W. ve Menges, J. I. (2013) "Biological Implicit Measures in HRM and OB: A Question of How Not if" Human Resource Management Review, 23(3):219-228.

Beugré, C. D. (2009) "Exploring The Neural Basis of Fairness: A Model of Neuro-Organizational Justice" Organizational Behavior and Human Decision Processes, 110(2): 129-139.

Beugré, C.D. (2010) "Brain and Human Behavior in Organizations: A Field of Neuro-Organizational Behavior" Edited by Angela A. Stanton, Mellani Day and Isabell
M.Welpe. Edward Elgar Publishing: Massachusetts USA 289-305.

Bevan, W. (1991) "Contemporary Psychology: A Tour Inside the Onion” American Psychologist, 46(5): 475-483.

Blakemore, S. J., Winston, J., ve Frith, U. (2004) "Social Cognitive Neuroscience: Where Are We Heading?" Trends in Cognitive Sciences, 8(5): 216-222.

Boyatzis, R. E., Passarelli, A. M., Koenig, K., Lowe, M., Mathew, B., Stoller, J. K., ve Phillips, M. (2012). Examination of the Neural Substrates Activated in Memories of Experiences with Resonant and Dissonant Leaders. The Leadership Quarterly, 23(2): 259-272.

Braeutigam, S. (2005) "Neuroeconomics-From Neural Systems to Economic Behaviour" Brain Research Bulletin, 67(5): 355-360.

Butler, M., ve Senior, C. (2007) "Toward an Organizational Cognitive Neuroscience" Annals of the New York Academy of Sciences, 1118(1): 1-17.

Cacioppo, J. T., ve Berntson, G. G. (1992) "Social Psychological Contributions to the Decade of the Brain: Doctrine of Multilevel Analysis" American Psychologist, 47(8): 1019-1028.

Camerer, C., Loewenstein, G., ve Prelec, D. (2005) "Neuroeconomics: How Neuroscience Can Inform Economics" Journal of Economic Literature, 18: 9-64.

Campbell, A., Whitehead, J., ve Finkelstein, S. (2009) "Why Good Leaders Make Bad Decisions" Harvard Business Review, 87(2): 60-66.

Cropanzano, R., ve Becker, W. J. (2013) “The Promise and Peril of Organizational Neuroscience Today and Tomorrow" Journal of Management Inquiry, 22(3): 306310.

Dietrich, A. (2004) “The Cognitive Neuroscience of Creativity” Psychonomic Bulletin \& Review, 11(6): 10111026.

Ergen, M., ve Y., Ülman. (2012) “Nörobilim, Nöroteknoloji, Yalan Tespiti ve Etik" Acıbadem Üniversitesi Sağlık Bilimleri Dergisi, 3(3): 149-157.

Finkelstein S ve D. C. Hambrick (1996) "Strategic Leadership: Top Executives and Their Effects on Organizations” West Publishing Company.

Fugate, D. L. (2007) “Neuromarketing: A Layman's Look at Neuroscience and its Potential Application to Marketing Practice" Journal of Consumer Marketing, 24(7): 385-394.

Glimcher, P. W., ve Rustichini, A. (2004) "Neuroeconomics: The Consilience of Brain and Decision" Science, 306(5695): 447-452. 
Hammond, D. C. (2011). "What is Neurofeedback: An Update” Journal of Neurotherapy, 15(4): 305-336.

Hammond, D. C., Bodenhamer-Davis, G., Gluck, G., Stokes, D., Harper, S. H., Trudeau, D. ve Kirk, L. (2011). "Standards of Practice for Neurofeedback and Neurotherapy: A Position Paper of The International Society for Neurofeedback \& Research" Journal of Neurotherapy, 15(1): 54-64.

Hills, J. (2012) "Neuroscience and talent: How neuroscience can increase successful execution of talent strategy". Human Resource Management International Digest, 20(3), 34-37.

Hills, J. (2013) "What should HR professionals know about neuroscience?” http://www.hrzone.com/talent/ retention/what-should-hr-professionals-know-aboutneuroscience (Erişim Tarihi: 17.03.2015)

Hines, T. (1987) "Left Brain/Right Brain Mythology and İmplications for Management and Training" Academy of Management Review, 12: 600-606.

Jeffery, R. (2013) “Neuroscience: HR's new secret weapon" http://www.cipd.co.uk/pm/peoplemanagement/b/ weblog/archive/2013/11/01/neuroscience-hr-s-newsecret-weapon.aspx (Erişim Tarihi: 17.03.2015)

Kenning, P., ve Plassmann, H. (2005) "Neuroeconomics: An Overview from an Economic Perspective" Brain Research Bulletin, 67(5): 343-354.

Keysers, C. (2010) "Mirror Neurons" Current Biology, 19 (21): 971-973.

King, R. G., \& Levine, R. (1993). Finance, entrepreneurship and growth. Journal of Monetary economics, 32(3), 513-542.

Lee, N., Broderick, A. J., ve Chamberlain, L. (2007) "What is 'Neuromarketing'? A Discussion and Agenda for Future Research" International Journal of Psychophysiology, 63(2): 199-204.

Leshner, A. I. (1991) "Psychology Research and NIMH: Opportunities and Challenges" American Psychologist, 46(9): 977-979.

Levine, D. K. (2011) “Neuroeconomics?” International Review of Economics, 58(3): 287-305.

Lindebaum, D. (2013) "Pathologizing the Healthy but Ineffective Some Ethical Reflections on Using Neuroscience in Leadership Research" Journal of Management Inquiry, 22(3): 295-305.

Lieberman, M. D. (2007) "Social Cognitive Neuroscience: A Review of Core Processes" Annu. Rev. Psychol, 58: 259-289.

Lord, R. ve Maher, K. (1991) Leadership and Information Processing: Linking Perception and Performance. Boston, MA: Unwin Hyman.
Martindale, K. (2014) "How can HR use neuroscience?" http://www.hrmagazine.co.uk/hr/features/1143430/ hr-neuroscience (Erişim Tarihi: 17.03.2015)

Meisinger, R. S. (2013) "Linking Neuroscience and HR". http://www.hreonline.com/HRE/view/story. jhtml?id=534355838 (Erişim Tarihi: 17.03.2015)

Miller, N. E. ve Dollard J. (1941) http://psycnet. apa.org/psycinfo/1942-00109-000 (Erişim Tarihi: 01/09/2014)

Mintzberg, H. (1976) "Planning on the Left and Managing on the Right" Harvard Business Review, 54(4): 4958.

Ochsner, K. N. (2004) "Current Directions in Social Cognitive Neuroscience" Current Opinion in Neurobio$\log y, 14(2):$ 254-258.

Ochsner, K. N., ve Lieberman, M. D. (2001) "The Emergence of Social Cognitive Neuroscience" American Psychologist, 56(9): 717.

Palmeri, T. J. (2013) "An Exemplar of Model-Based Cognitive Neuroscience" Trends in Cognitive Sciences, $67-$ 69

Pennington, D.C. (2000). Social cognition. Psychology Press. https://www.google.com.tr/books?hl=tr\&lr=\&id=9 $5 \mathrm{kfaysaFu} 8 \mathrm{C} \&$ oi $=$ fnd $\& \mathrm{pg}=\mathrm{PR} 13 \& \mathrm{dq}=$ Pennington + cog nition\&ots $=$ sx $5 \mathrm{kM} 1 \mathrm{TxzQ} \&$ sig $=S 1 \mathrm{a} 6 \mathrm{hmtORUect0eGU}$ ray8qhIdo\&redir_esc $=\mathrm{y} \# \mathrm{v}=$ onepage $\& \mathrm{q}=$ Pennington $\% 20$ cognition \&f=false (Erişim Tarihi: 16.03.2015)

Peterson, R. L. (2005) "The Neuroscience of Investing: FMRI of The Reward System" Brain Research Bulletin, 67(5): 391-397.

Poldrack, R. A. (2006) "Can Cognitive Processes be Inferred from Neuroimaging Data?" Trends in Cognitive Sciences, 10(2): 59-63.

Redish, A. D., Jensen, S., ve Johnson, A. (2008) “A Unified Framework for Addiction: Vulnerabilities in The Decision Process" Behavioral and Brain Sciences, 31(04): 415-437.

Rizzolatti, G., ve Craighero, L. (2004) "The MirrorNeuron System” Annu. Rev. Neurosci, 27: 169-192.

Rustichini, A. (2005) "Introduction - Neuroeconomics: Present And Future" Games and Economic Behavior, 52: 201-212.

Sadler-Smith, E., Hodgkinson, G. P., ve Sinclair, M. (2008) "A Matter of Feeling? The Role of Intuition in Entrepreneurial Decision-Making and Behavior" Research on Emotion in Organizations, 4: 35-55.

Scherg, M. (1990) "Fundamentals Of Dipole Source Potential Analysis Auditory Evoked Magnetic Fields And Electric Potentials" Advances in Audiology, 6: 40-69. 
Senior, C., Lee, N., ve Butler, M. (2011) "Organizational Cognitive Neuroscience" Organization Science 22: 804-815.

Sherrington, C. (1947) "The Integrative Action of The Nervous System" CUP Archive.

Waldman, D. A., Balthazard, P. A., ve Peterson, S. J. (2011) "Social Cognitive Neuroscience And Leadership" The Leadership Quarterly, 22(6): 1092-1106.

Waldman, D. A., Balthazard, P. A., ve Peterson, S. J. (2011b) "Leadership and Neuroscience: Can We Revolutionize The Way That Inspirational Leaders are Identified and Developed?" The Academy of Management Perspectives, 25(1): 60-74.
Waytz, A. ve Mason, M. "Your Brain at Work" Harward Business Review, https://hbr.org/2013/07/yourbrain-at-work/ar/1 (Erişim Tarihi: 17.03.2015)

http://www.columbia.edu/cu/psychology/courses $/ 1010 / \mathrm{mangels} /$ neuro/history/history.html $(05 / 06 / 204)$

https://www.humanbrainproject.eu/ (22/08/2014)

http://www.nih.gov/science/brain/ (22/08/2014) 
